\title{
Peritonit Sırasında Gelişen Orta Dereceli Endotoksikozu Belirleyen İşaretleyicilerin Seçilmesi
}

\author{
SELECTION OF BIOMARKERS THAT DETERMINES THE MODERATE ENDOTOXICOSIS DURING \\ PERITONITIS
}

\author{
Mushvig C. HASANOV \\ Azerbaycan Tıp Üniversitesi Genel Cerrahi Anabilim Dalı, Bilimsel Araştırma Merkezi Ve Medi Lux Özel Kliniği
}

\section{öz}

Amaç: Peritonit, acil cerrahi gerektiren hastalıklar arasında ön sıralarda yer alır ve tedavi araçlarının her geçen gün iyileştirilmesi, yeni tanısal araçların uygulanmasına karşın az gelişmiş bölgelerde yüksek bir ölüm oranına sahiptir. Bu çalışmanın amacı, peritonitli hastalarda gelişebilecek endotoksikozun ağırlık derecesini, az gelişmiş bölgelerde de değerlendirmek için basit muayene yöntemleri seçerek bir algoritma oluşturmaktır.

Gereç ve Yöntem: Çalışmaya orta ağırlık dereceli endotoksikoz saptanan 36 kişi dahil edilmiştir.

Bulgular: Çalışmaların sonucunda hastalarda kalp atım sayısı 110 - 130, arteriyel kan basıncı 70 - 120 / 45-80 mmHg, günlük idrar çıkışı 700 - 980 ml, kanda BUN değeri 8,3 $15 \mathrm{mg} / \mathrm{dl}$, malondialdehit konsantrasyonu 130 - 265,2 mmol/l, lipid peroksit konsantrasyonu 2,6 - 4,4 E/l, CRP değeri 0,4 - 0,45 mg/l, peritoneal eksüdada paramecium yaşama süresi 840 - 1450 saniye, malondialdehit $120-360 \mathrm{mmol} / \mathrm{l}$, hidrojen peroksit konsantrasyonu 0,17 - 0,32 mmol/l, lipid peroksit konsantrasyonu 2,8 - 4,3 E/l, katalaz konsantrasyonu $0,03-0,31 \mathrm{mg} / \mathrm{l}$, genel antioksidan etkinliği 17 - 35\%, CRP konsantrasyonu 0,23 - 0,57 $\mathrm{mg} / \mathrm{l}$ arasında değişmektedir.

Sonuç: Yaptığımız araştırmalar temelinde peritonit sırasında gelişen endotoksikozu değerlendirmek için bir algoritma oluşturulmuş ve bu algoritma temelinde peritonit sırasında gelişen endotoksikozun ağırlık derecesini değerlendirmek mümkün olmuştur.

Anahtar sözcükler: Peritonit, endotoksikoz, ağırlık derecesinin değerlendirilmesi

ABSTRACT

Objective: Peritonitis that require urgent surgical intervention takes place in the forefront and despite of the improvement in means of treatment, and the implementation of new diagnostic tools, each passing day, has a high mortality rate in

Mushvig C. HASANOV Azerbaycan Tip Üniversitesi Genel Cerrahi Anabilim Dalı Bilimsel Araştırma Merkezi Ve Medi Lux Özel Kliniği Bakü, AZERBAYCAN less developed regions. The purpose of this study, the moderate endotoxicosis may develop in patients with peritonitis, the less developed regions as well by selecting simple, inspection methods to evaluate a create of algorithm.

Material and methods: There were 36 patients who had moderate endotoxicosis included the study in 2007 - 2013.

Results: The minimum-maximum values of heart beats per minute were $110-130$, arte- 
rial blood pressure were 70 - 120 / 45 - $80 \mathrm{mmHg}$, the amount of daily diuresis were 700 to $980 \mathrm{ml}$,

the amount of blood BUN 8.3 to $15 \mathrm{mg} / \mathrm{dl}$, malondialdehyde concentration 130 to $265.2 \mathrm{mmol} / \mathrm{l}$, lipid peroxide concentration 2.6 to $4.4 \mathrm{E} / \mathrm{l}$, CRP concentration 0.4 to 0 , $45 \mathrm{mg} / \mathrm{l}$, in the survival time of paramecium in peritoneal exudate were $840-1450$ seconds, peritoneal malondialdehyde concentration 120 to $360 \mathrm{mmol} / \mathrm{l}$, hydrogen peroxide concentration 0.17 to $0.32 \mathrm{mmol} / \mathrm{l}$, lipid peroxide concentration 2.8 to $4.3 \mathrm{E} /$ l, catalase concentration 0.03 to $0.31 \mathrm{mg} / \mathrm{l}$, of the overall antioxidant activity 17 - 35\%, CRP concentrations 0.23 to $0.57 \mathrm{mg} / 1$.

Conclusion: Results of our research were created an algorithm to evaluate endotoxicosis during peritonitis and has been able to assess the moderate endotoxicosis.

Keywords: Peritonitis, endotoxicosis, assessment of severity

Peritonit ve komplikasyonları cerrahi alanında önemli sorunlardan biridir. Peritonit, acil cerrahi gerektiren hastalıklar arasında ön sıralarda yer alır ve tedavi araçlarının her geçen gün iyileştirilmesi, yeni tanısal araçların uygulanmasına karşın az gelişmiş bölgelerde yüksek bir ölüm oranına sahiptir (1-3). Peritonit nedeniyle yaşanan ölümlerin temel nedenlerinden biri ve en önemlisi endotoksikozdur. Endotoksikozun peritonit sırasında bağırsak patojen mikroflorasının karın boşluğuna geçmesi ile dokularda oluşan yıkıcı süreçlerden gelişen toksik maddelerin ve bozulan doku metabolizması sonrası oluşan metabolitlerin periton sıvısına geçmesi; bunun vücuda rezorbsiyonu sonucu gelişen çok nedenli patolojik bir süreç olduğu literatürde belirtilmiştir $(4,5)$. Endotoksikoz, ağırlık derecesine göre çoklu organ yetmezliğine neden olarak, yaşamsal fonksiyonları etkiler ve ölüm riskini yükseltir. Bu nedenle endotoksikozun ağırlık derecesinin değerlendirilmesi peritonitin tedavisi için önemli noktalardan biri olarak kabul edilir.

Literatürde peritonit kaynaklı endotoksikozun ağırlık derecesini değerlendirmek için çeşitli yöntemler (Sofa, APACHE-I-II, SSS, Manxaymerin peritoneal endeksi vb.) verilmiştir. Ancak endotoksikozun ağırlık derecesini bu yöntemler aracılığı ile değerlendirmek için yüksek teknoloji gerektiren incelemeler yapılmalıdır. Bu çalışmanın amacı, peritonitli hastalarda gelişebilecek endotoksikozun ağırlık derecesini az gelişmiş bölgelerde de değerlendirmek için basit muayene yöntemleri seçerek bir algoritma oluşturmaktır.

\section{GEREÇ VE YÖNTEM}

Çalışmaya 2007-2013 yıllarında Medi Lüx Özel Klini- ğine acil olarak başvuran ve Savçuk'un verdiği sınıflandırma uyarınca peritonitin toksik aşamasında yani patolojik sürecin ilk belirtilerinin ortaya çıtı̆̆ 1 ilk 24-48 saat içinde değerlendirilen 36 hasta alınmıştır (6). Olguların 14'ünde laparoskobik, 22'sinde laparatomi ile acil cerrahi girişim uygulanmış ve peritonit nedeni ortadan kaldırılmıştır. Olgulardaki peritonitin etiyolojik nedenleri Tablo I'de verilmiştir.

Tablo I. Olgulardaki peritonitin etiyolojik nedenleri

\begin{tabular}{llr}
\hline Görülme sıklığı & Nedenleri & $\mathbf{n} \%$ \\
\hline 1 & Safra kesesi perforasyonu & 1027,8 \\
2 & Apendiks perforasyonu & 822,2 \\
3 & Mide ülseri perforasyonu & 719,4 \\
4 & Over kist torsiyonu & 616,7 \\
5 & İnce bağırsak tıkanıklığ1 & 513,9 \\
\hline
\end{tabular}

Endotoksikozun ağırlık derecesini değerlendirmek amacıyla aşağıdaki incelemeler yapılmıştır:

1. Bir dakikadaki kalp atım sayısı

2. Arteriyel kan basincı ( $\mathrm{Hg} \mathrm{mm}$ )

3. Günlük idrar miktarı (ml)

4. Kanda BUN miktarı (mg / d 1$)$

5. Kanda malon dialdehit konsantrasyonu ( $\mathrm{mmol} / \mathrm{l})$

6. Kanda lipid peroksit konsantrasyonu (mmol/ l)

7. Kanda C-reactive Protein (CRP) konsantrasyonu (mg/l)

Cerrahi işlem sırasında karın boşluğundan alınan periton sıvısında aşağıdaki incelemeler yapılmıştır:

1. Paramecium (Unicellular Ciliated Protozoa) ortamda yaşama süresi (sn) 
2. Malondealdehit konsantrasyonu ( $\mathrm{mmol} / \mathrm{l})$

3. Hidrojen peroksit konsantrasyonu ( $\mathrm{mmol} / \mathrm{l})$

4. Lipid peroksit konsantrasyonu (E/l)

5. Katalaz enziminin etkinliği (\%)

6. Genel antioksidan etkinliği (\%)

7. CRP konsantrasyonu $(\mathrm{mg} / \mathrm{l})$

Kanda BUN ölçümleri "Bioskrem" mikroanalizör yöntemi ile yapılmıştır. CRP konsantrasyonu Pancov yöntemi ile spektrofotometik olarak 230-280 nm dalga boyunda belirlenmiştir (7). Periton sıvısının hazırlığı ve toksisite göstergesi Paramecium ortamda yaşama süresi (sn), Bakü Tıp Üniversitesi Araştırma Merkezinde geliştirilen yöntemle yapılmıştır (8). Hazırlanmış eksüdada toksisite, malon dealdehit ve Lipid peroksit konsantrasyonu, Uchijama ve Michara metoduna yapilan modifikasyon temelinde kabul edilen yöntemler ile belirlenmiştir (9-11). Genel antioksidan etkinliği ise Spektor tarafında geliştirilen yöntemle tayin edilmiştir (12). Katalaz tayini "Qedon Richter" kit ile "Bioskrem" mikroanalizöründe yapılmıştır. Değişkenlerin ortalama, standart hata, minimum ve maksimum değerleri saptanmıştır. İstatistiksel anlamlılık düzeyi olarak $p<0,05$ kabul edilmiştir. Olguların peritonit sonrası değerleri ile karşılaştırılmasında normal dağılıma uymayan değişkenler için Wilcoxon signed-rank test, varyans analizi için Van der Waerden (VW) testi uygulanmıştır.

\section{Sonuçlar}

Gözlem altındaki olguların \%100'ünde dakikadaki kalp hızı peritonit sonrasına göre daha yüksek (110-130 mm Hg) olarak saptanmıştır. Sistolik kan basıncı seviyesi ise $70-120 \mathrm{~mm} \mathrm{Hg}$ arasında değişmiş ve hastaların \%50'sinde hipotonik bulunmuştur. Diyastolik kan basıncı seviyesi ise $45-80 \mathrm{~mm} \mathrm{Hg}$ arasında değişerek hastaların $\% 47$ 'sinde hipotoni saptanmıştır. Günlük idrar çıkış miktarı tüm hastalarda normale göre azalarak 700-980 ml arasında bulunmuştur. Yapılan kan tahlilleri sonucunda, kanda BUN miktarı artarak 8,3-15 mg/dl arasında değiştiği gözlemlenmiştir. Bu artış hastaların \%94'ünde saptanmıştır. Kanda malondialdehit konsantrasyonu 130265,2 mmol/1 arasında değişmiştir. Gözlem altında olan tüm hastalarda kan malondialdehit konsantrasyonu artmıştır. Malondialdehit konsantrasyonuna uygun olarak kanda lipid peroksit konsantrasyonu 2,6-4,4 E/1 arasında değişerek normalden yüksek bulunmuştur. Belirtilen artış hastaların \%100'ünde gözlenmiştir. Olguların \%100'ünde kanda CRP konsantrasyonu artarak 0,4-0,45 mg/l arasında değişmiştir. Cerrahi işlem sırasında karın boşluğundan aldığımız eksüdanın içeriğinde Parameciumların \%100'ünün ortandan yok olma süresi 840-1450 saniye arasında gerçekleşmiştir. Eksüda malondealdehit konsantrasyonu ise 120-360 mmol/l; hidrojen peroksit konsantrasyonu 0,17-0,32 mmol/l; lipid peroksit konsantrasyonu 2,84,3 E/L arasında değişmiştir. Karın boşluğundan alınan eksüdanın içeriğinde antioksidan savunma sistemini değerlendiren markerler ölçülmüştür. Katalaz konsantrasyonu 0,03-0,31 mg/l arasında, genel antioksidan etkinliği ise \%17-35 arasında değişmiştir. CRP konsantrasyonu ise 0,23-0,57 mg/l arasında saptanmıştır. Kan ve periton sıvısinda yapılan ölçüm değerleri Tablo II'de verilmiştir.

Elde edilen sonuçlar ile peritonit sırasında gelişen endotoksikozu değerlendirmek için aşağıdaki algoritma oluşturulmuştur:

1. Dakikadaki kalp atım sayısı: $110-130$

2. Sistolik kan basınc1: $70-120 \mathrm{mmHg}$

3. Diastolik kan basıncı: $45-80 \mathrm{mmHg}$

4. Günlük idrar miktarı: 700-980 ml

5. Kanda BUN düzeyi: 8,3-15 mg/dl

6. Kanda malondialdehit konsantrasyonu: 130-265,2 $\mathrm{mmol} / \mathrm{l}$

7. Kanda lipid peroksit konsantrasyonu: 2,6-4,4 E/L

8. Kanda CRP konsantrasyonu: 0,4-0,45 mg/1

9. Peritoneal eksüdada paramecium yaşama süresi: 840 1450 sn

10. Peritoneal eksüdada malondialdehit konsantrasyonu: 120-360 mmol/1

11. Peritoneal eksüdada hidrojen peroksit konsantrasyonu: $0,17-0,32 \mathrm{mmol} / \mathrm{l}$

12. Peritoneal eksüdada lipid peroksit konsantrasyonu: 2,8-4,3 E/1

13. Peritoneal eksüdada katalaz konsantrasyonu: 0,03-0,31 $\mathrm{mg} / \mathrm{l}$

14. Peritoneal eksüdada genel antioksidan etkinliği: \%17-35

15. Peritoneal eksüdada CRP konsantrasyonu: 0,23-0,57 mg/l 
Tablo II. Orta dereceli peritoneal endotoksikoz tanısı konulan hastalarda yapılan klinik ve fizik bakı sonuçları

\begin{tabular}{lcc}
\hline Değişken & Ortalama \pm SD & $p$ \\
\hline Kalp atım sayısı & $120,500 \pm 1,100$ & $<0,001$ \\
Sistolik kan basıncı (mmHg) & $96,900 \pm 2,000$ & $<0,001$ \\
Diastolik kan basıncı (mmHg) & $59,400 \pm 1,600$ & $<0,001$ \\
Günlük idrar çıkışı (ml) & $846,400 \pm 12,200$ & $<0,001$ \\
Kan BUN düzeyi (mg/dl) & $10,700 \pm 0,300$ & $>0,05$ \\
Kan MDA (mmol/l) & $205,2000 \pm 5,300$ & $<0,001$ \\
Kan lipid peroksit (E/l) & $3,790 \pm 0,050$ & $<0,001$ \\
Kan CRP (mg/l) & $0,421 \pm 0,003$ & $<0,001$ \\
PE paramecium yaşam süresi (sn) & $1165,600 \pm 27,800$ & $<0,01$ \\
PE MDA (mmol/l) & $220,000 \pm 10,600$ & $<0,01$ \\
PE hidrojen peroksid (mmol/l) & $0,248 \pm 0,008$ & $<0,01$ \\
PE lipid peroksit (mmol/l) & $3,340 \pm 0,060$ & $<0,01$ \\
PE katalaz (mg/l) & $0,195 \pm 0,090$ & $<0,01$ \\
PE toplam antioksidant etkinlik (\%) & $25,800 \pm 0,700$ & $<0,01$ \\
PE CRP (mg/l) & $0,383 \pm 0,017$ & $<0,01$ \\
\hline
\end{tabular}

* PE: Peritoneal eksüda

\section{TARTIŞMA}

Organizmanın peritoneal endotoksikoza ilk yanitlarından biri kalp-damar sistemi tarafından verilir. Arteriyel basıncın düşmesini telafi etmek amacıyla kalp atım sayısı artar. Sonuçlarımız bu durumu desteklemektedir. Diastolik basınç için de benzer bulunmuştur. Bilindiği gibi, peritoneal endotoksikoz etkisi ile böbreklerin fonksiyonunun bozulmasının ilk belirtilerinden biri günlük diürezin miktarının azalmasıdır. Buna uygun olarak bizim yaptığ1mız çalışmada hastaların \%100'ünde idrar çıkışının azalması ve böbreklerin fonksiyonunda patolojik değişikliklerin olduğunu göstermektedir. Bu araştırmadan yola çıkarak dakikada kalp atışının 110-130 arasında, sistolik ve diastolik basınç seviyesinin sırasıyla $70-120$ ve $45-80$ mmHg arasında, günlük idrarın miktarının 700-980 ml arasında olması orta dereceli peritoneal endotoksikozun karakteristik belirtisi olarak değerlendirilmelidir. Kanda belirlenen biyokimyasal göstergelerde düzenli bir şekilde değişmiştir. Kanda BUN miktarı böbreklerin fonksiyonel durumunu yansıtan marker olarak kabul edilmiştir. Bizim araştırmamız gösteriyor ki hastaların \%94'ünde kanda BUN miktarının yükselmesinin nedeni endotoksikoz etkisiyle böbreklerin fonksiyonel durumunda meydana gelen değişikliklerdir. CRP'nin inflamasyon markeri gibi değer- lendirilmesi de çoğu yazarlar tarafından kabul edilmiştir $(13,14)$. Bu açıdan hastaların \%100'ünde kanda CRP konsantrasyonunun yükselmesi orta dereceli endotoksikozu değerlendiren güvenilir bir işaretleyici olarak değerlendirilmelidir.

Endotoksikozun karakteristik özelliklerinden biri de hücre zarında yıkıcı etki göstermesidir. Hücre zarı hasarının temel göstergelerinden birisi de kanda lipid peroksitlerinin artışıdır $(15,16)$. Bu açıdan bizim aldığımız sonuçlar, yani hastaların \%100'ünde kanda lipid peroksidasyonunun başlangıç ve son ürünlerinin yükselmesi dikkat çekicidir ve endotoksikoz açısından anlamlıdır. Bu bilgilerden yola çıkarak, peritonitli hastaların kan BUN miktarının 8,3-15 mg/dl, CRP konsantrasyonunun 0,40$0,45 \mathrm{mg} / \mathrm{l}$. malondialdehit ve lipid peroksitin sirasıyla 130265, $2 \mathrm{mmol} / \mathrm{l}$ ve 2,6-4,4 E/1 arasinda olması orta dereceli endotoksikozun en önemli göstergesi olarak değerlendirilmelidir.

Peritoneal eksüdanın yapısı da orta dereceli endotoksikoz için bilgilendiricidir. Öyle ki, peritonit için karakteristik belirtilerden biri de peritoneal eksüdanın toksikliğidir (8). Bizim yaptığımız incelemeler de bunu desteklemektedir. Hastaların karın boşluğuna biriken eksüda ortamında paramecium yaşama süresi $840-1450$ saniye arasında 
kaydedilmiştir. Buna uygun olarak malondialdehit konsantrasyonu 120-130 mmol/l, hidrojen peroksit konsantrasyonu 0,17-0,32 $\mathrm{mmol} / \mathrm{l}$, lipid peroksit konsantrasyonu ise 2,8-4,3 E/l arasında saptanmıştır. Peritoneal eksüdaya toksik özellik veren faktörlerden birisi de lipid peroksidasyon ürünleridir. Bu görüş Azerbaycan Tıp Üniversitesi Bilimsel Araştırma Merkezi'nde yapılan araştırmalar tarafından da gösterilmiştir (4,17-19). Peritoneal eksüdada lipid peroksidasyonunun artması sonucu intraabdominal antioksidan savunma sisteminin göstergelerinden olan katalaz ve toplam antioksidan aktivite azalmıştır. Hastaların da peritoneal eksüdasında katalaz etkinliği 0,030,31 mg/l genel antioksidan etkinliği ise \%17-35 arasında bulunmuştur. İnflamasyon ve aynı zamanda endotoksikoz göstergesi olan CRP konsantrasyonunda yaşanan değişim de, peritonit sırasında gelişen intoksikasyonun tanısında önemli bir rol oynayacaktır.

\section{SONUÇ}

Sonuç olarak yaptığımız araştırmalar temelinde önerdiğimiz algoritmadan yararlanılarak peritonit sırasında gelişen endotoksikozun derecesi hakkında fikir edinilebilir.

\section{KAYNAKLAR}

1. Isaev QB. Teşhis posleoperaцionnoqo peritonita. Xirurqiy ol 2002; 6:27-29.

2. Hadiyev SI, Abdinov MÖ. Irinli peritonitlerde karm boşluğunun drenleşdirilmesi. Sağlık 2006; 3: 179-182.

3. Gurbanov FS, Veliyev NE, Esedov ŞE. Klinik peritonologiya. Bakü 2014; 1: 483.

4. Garayev QŞ, Aliyev SC, Cavadova CT ve ark. Peritonit sırasında peritoneal eksudatın bünyesinde lipid peroksidleşmesinin durumu. Sağlık 2005; 5: 83-85.

5. Guevara M, Terra C, Nazar A, et al. Albumin for bacterial infections other than spontaneous bacterial peritonitis in cirrhosis: A randomized, controlled study. Journal of Hepatology 2012; 4: 759- 765.

6. Savçuk BD. Qnoy்nıx peritonit. Medicine 1979; 1: 343.

7. Pankov VN, Sadkov SA, Sitnikov SA, et al. Molekuli sredneỷ Massi kak pokazatelb stepenb naruşeniy ol qemokoaquly ol цii pri qemofilii. Lab Delo 198; 9: 23-25.
8. Qaraev QŞ, Aliev SDj, Dadaşova NR, et al. Znaçenie test parameцiỳ voцenke toksiçnosti peritonealınoqo èksudata. Biomediцina 2004; 3: 33-37.

9. Pafomov QA, Burdiça FA, Şirinova MN. Ekspres-metot opredeleniy ol toksiçqosti krovi i limfi s pomощьуu paramеціy் pri èkzoèndotoksikozax. Sov mediцina 1980; 1:117-119.

10. Uchiyama M, Michara M. Determination of malondealdehyde in tissues bu thiob rabiture acid test. Biochem 1978; 1: 271-278.

11. Stalbnayol İD. Yöntem opredeleniy ol dienovoy் konbyu qantı nenasıщennıx vısşix jirnıx kislot. Sovremennıe metodı v bioximii M.Mediцinı 1997; 1: 63-64.

12. Spektor EV, Ananenko AA, Politova LN. Yöntem opredeleniy ol antiokislitelınoy் aktivnosti sıvorotki krovi. Lab Delo 1984; 1: 26-29.

13. Eryuxin İA, Beliy VY. Rolb MSM v patoqeneze èndotoksikoza pri peritonite. Vestnik xirurqiy ol 1987; 1: 47-51.

14. Vasilinçuk VV, Vovk ĖV. Urovenь srednix molekül kak pokazatelb virajennosti èndotoksikoza pri ostrom peritonite. V kn: Sovremennie voprosi detoksikaцii. Andijan 1988; 1: 45-46.

15. Alieva AE். Оцеnka intensivnosti perekisnoqo okisleniy ol lipidov iurovny ol ėndotoksikoza u bolbnıx s xroniçeskoy poçeçnoỷ nedostat oçnostbyu. Sağlık 2004; 1:84-85.

16. Quliyeva FE. Kronik böbrek yetmezliği olan hastalarda lipidperoksidleşmesi süreçlerinin immunoqlobulinlerin aktivliyine etkisinin öğrenilmesi. Azerb Tıp Dergisi 2007; 1:86-88.

17. Hadıyev SI, Abdinov MÖ. Mide ülseri perforsyonu sırasında gelişmiş peritonitlerde peritoneal eksudatda lipid peroksidleşmesi ürünlerinin hastalığın fazalarından bağlı olarak değişmesi. Sağlık 2005; 8:137- 139.

18. Memmedov EM, Abdullayev MM, Ramazanov CN. Endotoksikozun kompleks tedavisinde kanın lazerle intravenöz şüalandırılmasının etkinliği. Azerb Tıp Dergisi 2012; 3:100-104.

19. Poca M, Concepcion M, Cass M, et al. Role of Albumin Treatment in Patients With Spontaneous Bacterial Peritonitis. Clinical Gastoenterology and Hepatology 2012; 3: 309-315. 